\title{
Fatores críticos na gestão de projetos: um estudo de caso numa grande empresa latino-americana de classe mundial
}

\section{Critical factors in project management: a case study in a big latin american world class company}

\author{
Ricardo Vinícius Dias Jordão ${ }^{1,2,3}$ \\ Fabiana Gonçalves Pelegrini ${ }^{4}$ \\ Anna Carolina Teddo Jordão ${ }^{5}$ \\ Ester Eliane Jeunon ${ }^{1}$
}

\begin{abstract}
Resumo: A pesquisa descrita neste artigo teve por objetivo analisar os fatores críticos de sucesso (FCS) no gerenciamento de projetos em uma empresa de grande porte. Os FCS indicam o risco de não alcançar os resultados finais previstos para os projetos. A análise qualitativa e quantitativa buscou investigar os potenciais ganhos que podem ser gerados a partir do conhecimento desses fatores. Os dados foram coletados a partir de um questionário aplicado a respondentes envolvidos com a atividade de projetos. Para a interpretação dos dados referentes ao desempenho e à importância atribuída aos critérios de avaliação dos FCS, foi avaliada a percepção dos entrevistados. Os resultados indicaram que, durante a condução de projetos, o acompanhamento de tais fatores de forma oportuna pode ser capaz de impedir o surgimento de problemas ou minimizar o efeito destes. Além disso, observou-se a relevância do acompanhamento constante dos processos empresariais, visando (1) conhecer melhor as atividades realizadas, de forma a identificar problemas potenciais e reais, (2) efetuar correções na dinâmica desses processos e (3) propor mudança nos métodos e ferramentas aplicadas na gestão de projetos.

Palavras-chave: Gestão de Projetos; Fatores Críticos de Sucesso; Análise e Gestão de Riscos; Inovação em Projetos; Empresa Latino-americana de Grande Porte.
\end{abstract}

\begin{abstract}
The research described in this paper aimed to analyze the critical success factors (CSF) in project management in a large company. The CSF indicates the risk of not reaching the estimated ending results of projects. The qualitative and quantitative analysis described in this paper aimed to investigate the potential gains that can be obtained from understanding these factors. The data was collected by means of a survey administered to respondents involved with project activities. The respondents' perception was analyzed with the purpose of both interpreting the performance related data and the importance assigned to the CSF evaluation criteria. The empirical results indicate that during the projects development, the activities of monitoring such factors in a timely manner may be possible to prevent the emergence of problems or minimize their negatives effects. Furthermore, it was observed the importance of ongoing monitoring of business processes in order to (1) better understand the activities undertaken in order to identify potential and actual problems, (2) perform corrections in the dynamics of these processes, and (3) propose changes in the methods and tools applied to project management.
\end{abstract}

Keywords: Project Management; Critical Success Factors; Management and Risk Analysis; Innovation in Project; Large Latin American Company.

\footnotetext{
${ }^{1}$ Fundação Pedro Leopoldo - FPL, Av. Lincoln Diogo Viana, 830, Dr. Lund, CEP 33600-000, Pedro Leopoldo, MG, Brasil, e-mail: jordaoconsultor@yahoo.com.br; ejeunon@gmail.com

${ }^{2}$ Center for Advanced Studies in Management and Economics (UE), Évora, Portugal

${ }^{3}$ Swiss Management Center, Zurique, Suíça

${ }^{4}$ Instituto de Ciências Exatas e Aplicadas - ICEA, Universidade Federal de Ouro Preto - UFOP, Rua 36, Número 115, Bairro Loanda, CEP 35931-008, João Monlevade, MG, Brasil, e-mail: fabianapelegrini@ yahoo.com.br

${ }_{5}^{5}$ Tecer Negócios e Melhorias Ltda, Rua Alegrete, 425/102, CEP 31353-180, Belo Horizonte, MG, Brasil, e-mail: annateddo@ hotmail.com Recebido em Nov., 11, 2013 - Aceito em Abr. 13, 2015
}

Suporte financeiro: Nenhum. 


\section{Introdução}

A gestão de projetos (GP) ganhou popularidade como um conceito de gestão distinto usado para conduzir não só os objetivos de negócios, mas também alguns aspectos da agenda de desenvolvimento econômico de países em desenvolvimento (Ofori, 2013). Um estudo promovido pela Harvard Business School (HBS) apontou que diversas têm sido as razões para a "explosão" do uso das técnicas de GP. Dentre elas, destacam-se o maior reconhecimento dos projetos como um fator-chave no atendimento dos objetivos estratégicos da organização e o aumento das pressões competitivas - que forçam a aumentos nos níveis de eficiência e eficácia gerencial e organizacional e a redução do tempo de ciclo de vida dos produtos (HBS, 1997). Internacionalmente, um projeto tem sido definido como um processo único, consistindo de um grupo de atividades coordenadas e controladas com datas para início e término, empreendido para o alcance de um objetivo conforme requisitos específicos, incluindo limitações de tempo, custo e recursos (ISO, 1997; Hwang \& Lim, 2013; Han et al., 2012), que compreende também a análise de riscos e do escopo em que deve ocorrer (Charvat, 2003). Tandon \& Mohanty (2003) complementam dizendo que um projeto consiste em uma organização de pessoas dedicadas, visando atingir um propósito/ objetivo específico.

Em uma visão mais contemporânea, o guia do Project Management Body of Knowledge (PMBOK) entende projeto como um esforço temporário empreendido para criar um produto, serviço ou resultado exclusivo, sendo a GP percebida como uma área gerencial que aplica conhecimentos, habilidades e técnicas na elaboração de atividades relacionadas para atingir um conjunto de objetivos predefinidos com prazo, custo e qualidade estabelecidos, através da mobilização de recursos técnicos e humanos (PMI, 2013). Nesse sentido, o sucesso da GP depende, em grande parte, do conhecimento dos fatores críticos de sucesso (FCS) usados para criar medidas que auxiliem na gestão, no controle e na correção das atividades, como também para apoiar e medir o sucesso de uma abordagem estratégica e tática da execução de projetos. Essa abordagem tem o intuito de promover o sucesso do sistema de entrega do projeto e apoiar a alocação adequada dos recursos limitados (Hwang \& Lim, 2013). Mesmo que alguns autores digam que o sucesso seja algo difícil de definir (Han et al., 2012), a definição clássica de sucesso do projeto consiste no atendimento a tempo, dentro do orçamento dos requisitos de qualidade dos produtos e/ou processos (Shenhar et al., 2001, Shenhar, 2004; Whitten, 2000). Segundo Wu \& Chen (2006), durante a condução de projetos, esses fatores se relacionam ao risco das atividades - que carecem de um acompanhamento oportuno e sistemático, visando impedir ou minimizar o surgimento de problemas ou o efeito deles.

Nos últimos anos, a investigação orientada ao contexto de FCS na GP gradualmente ganhou interesse (Han et al., 2012). Não obstante, Yaraghi \& Langhe (2011) asseveram que, apesar da existência de extensa literatura sobre gestão de risco, ainda há uma carência de um padrão ou diretriz que possa tanto ajudar a todas as organizações a terem projetos bem-sucedidos, quanto colaborar para que elas implementem seu sistema de gestão de riscos, sem limitações por tipo de negócio. Eles reconhecem que houve alguns esforços valiosos para a adoção de normas e diretrizes de gestão de risco, mas ainda não têm nem aceitação global, nem a universalidade exigida. Esses autores ressaltam que há um desejo no campo da gestão para desenvolver um corpo de conhecimentos relacionados aos FCS. Além disso, elucidam a importância de perceber como esses fatores se relacionam entre si e como as estratégias de gestão de riscos podem ser definidas, monitoradas e controladas para fornecer um tratamento adequado a esses fatores.

Assim, com o intuito de analisar o efeito dos fatores críticos de sucesso na gestão de projetos, tomou-se aqui como objeto de estudo a empresa Alpha (nome fictício por razões de confidencialidade), uma companhia latino-americana em que a atividade de projetos é fundamental em seus processos. A empresa Alpha é a maior empresa privada na América Latina, a segunda maior mineradora diversificada do mundo e a maior empresa das Américas em valor de mercado, assim como uma das 30 maiores companhias públicas negociadas no mundo e a maior produtora e exportadora mundial do produto que fabrica.

O objetivo da pesquisa descrita neste artigo foi, portanto, analisar os FCS no gerenciamento de projetos em uma empresa latino-americana de grande porte. A análise pautou-se em aspectos relacionados às competências necessárias para a eficiência e eficácia da GP. O foco da análise foram os FCS no curto prazo em uma equipe de processo. Como objetivos secundários têm-se: a) avaliar a visão dos diferentes níveis hierárquicos (colaboradores juniores, seniores e de nível gerencial) sobre a GP, b) analisar os atuais gargalos dos processos e c) diagnosticar as atividades, os métodos e ferramentas aplicadas na GP na empresa.

Além de contar com as recomendações de autores como Alves et al. (2013), a pesquisa justifica-se em função de suas contribuições teóricas e práticas. Em termos teóricos residem do acesso a informações em uma empresa desse tamanho e importância, promovendo o cotejamento dos resultados ora observados com estudos anteriores, além da inovação metodológica trazida pela estratégia de observação participante. Em termos práticos, faz-se relevante para todos executivos e empresas que precisam melhor 
compreender as práticas de GP e, muitas vezes, não têm acesso à realidade de grandes empresas. Adicionalmente, a pesquisa inovou ao focar na GP no curto prazo - que é um dos principais gargalos no estudo dos FCS, uma vez que as ações devem ser dinâmicas para mitigar e/ou reduzir os riscos inerentes aos processos e as atividades, tema pouco explorado na realidade brasileira.

Adicionalmente, Hwang \& Lim (2013) lembram que devido, à atual complexidade do ambiente de negócios, a indústria deve estar preparada para gerir as obrigações contratuais, protocolos de regulação e financiamento de projetos, mantendo o ritmo das mudanças tecnológicas e atendendo às crescentes demandas de uma população que exige produtos mais sofisticados e de qualidade. Em tal situação, o desenvolvimento de um quadro estratégico que taticamente lida com o sucesso do projeto e a identificação dos FCS é um importante ponto de partida. Assim, a identificação dos FCS (em cada empresa) aumenta a probabilidade de sucesso dos projetos e melhora a predição de resultados. Esses autores esclarecem que isso justifica a realização desse tipo de pesquisa, ponderando que desse modo a gerência pode tomar as medidas necessárias para: (1) evitar o fracasso do projeto, (2) identificar os projetos promissores que poderiam ser desenvolvidos e (3) identificar as áreas problemáticas do projeto para realizar as ações corretivas necessárias. Essas três medidas são fundamentais para a busca da excelência na GP, sendo elas ainda essenciais para manter a competitividade das empresas em uma economia globalizada.

Como implicações gerenciais da pesquisa, ressalta-se a identificação dos FCS na empresa estudada e dos indicadores-chave de desempenho que podem ajudar a mapear, avaliar e melhorar o desempenho da GP em situações parecidas. Tal processo de benchmarking permitiria que outras empresas similares pudessem adotar as melhores práticas de outras (como as ora descritas) para apoiar os seus esforços de melhoria contínua e para ajudá-las a manterem-se competitivas, ampliando a relevância do estudo e justificando igualmente sua execução. Este artigo foi estruturado em cinco seções: introdução, referencial teórico, metodologia, apresentação e análise do caso e, por fim, as considerações finais, seguidas das referências utilizadas.

\section{Fatores críticos no gerenciamento de projetos}

Muitos estudos, como os de Hwang \& Lim (2013), Yaraghi \& Langhe (2011), Alves et al. (2013), Vezzoni et al. (2013), Ofori (2013) e Morioka \& Carvalho (2014) procuraram entender os fatores que levam os projetos a um desempenho superior no mercado. O desempenho de um projeto está intimamente ligado na forma com a qual o projeto é conduzido e gerenciado. A GP existe para traçar, divulgar, monitorar e corrigir a rota dos projetos. Adicionalmente, ela cuida de questões, riscos, incertezas, imprevistos, falhas e mudanças que surgem ao longo dos processos, funções e atividades empresariais. Sendo assim, a GP inclui (i) a identificação das necessidades; o (ii) o estabelecimento de objetivos claros e alcançáveis; (iii) o balanceamento das demandas conflitantes de qualidade, escopo, tempo e custo; (iv) a adaptação das especificações, dos planos e da abordagem às diferentes preocupações e, ainda, (v) as expectativas das diversas partes interessadas. Segundo o guia PMI (2013), a adequada GP passa pela aplicação e integração de cinco grupos de processos, conhecidos como ciclo de vida do projeto: iniciação, planejamento, execução, monitoramento e controle e encerramento. Tais processos são divididos em outros 47 processos de gerenciamento de projetos, agrupados em dez áreas de conhecimentos que representam um conjunto completo de conceitos, termos e atividades que compõem um campo profissional, campo de gerenciamento de projetos ou uma área de especialização. Elas são integração, tempo, custo, prazo, comunicação, risco, qualidade, aquisição, recursos humanos e partes interessadas. Nesse sentido, a GP requer aprimoramento da administração dessas dez áreas de conhecimento vinculadas a processos gerenciais, buscando a harmonização dos diversos elementos-chave de um projeto, pois a excelência nessas áreas, embora um grande desafio, é um fator promotor do alcance do sucesso na GP.

Os resultados de estudos empíricos indicam que os fatores críticos que contribuem para o sucesso de um projeto incluem apoio da alta administração, comunicação eficaz, clareza de propósitos e objetivos do projeto, e participação das partes interessadas (Ofori, 2013), sendo que há um impacto significativo da tipologia de projetos sobre o desempenho de determinados FCS, evidenciando a importância de definir critérios objetivos de classificação de projetos (Morioka \& Carvalho, 2014).

O conceito de FCS foi introduzido primeiramente por Rockart (1979) em seu artigo "Chief executives define their own data needs", definindo-os como: um limitado número de áreas nas quais os resultados, se satisfatórios, irão assegurar um desempenho competitivo de sucesso para a organização. Esse autor alerta ainda que as áreas-chave da GP demandam um cuidado constante da administração.

As áreas consideradas como as que impactam nos FCS na GP por diversos autores são: prazo, custo, escopo e qualidade (Dinsmore, 2007; Ofori, 2013; Han et al., 2012). Já Pinto \& Slevin (1987) apontam quatro critérios: tempo, custo, eficácia e satisfação do cliente, coadunando com a abordagem de Hwang \& Lim (2013). Estes últimos autores 
complementam dizendo que os FCS possuem quatro categorias principais: (1) características do projeto, (2) as disposições contratuais, (3) os participantes do projeto, e (4) processos interativos.

Segundo Yaraghi \& Langhe (2011), os FCS são definidos a partir de três perspectivas diferentes: (1) os fatores que têm influência sobre a inclinação e disposição de uma empresa para a execução da gestão de risco; (2) os fatores que são importantes durante a concepção e implementação da gestão de risco em uma empresa e podem afetar significativamente o sucesso e implementação do projeto; e (3) os fatores que são de importância crucial para executar com êxito, manter e administrar a gestão de risco após o encerramento do projeto de concepção e implementação do sistema de gestão de riscos.

As diferentes visões supramencionadas são complementares para entender os FCS na GP, pois como já argumentavam Kloppenborg \& Opfer (2002), Raz et al. (2002), Shenhar et al. (2001) e Shenhar (2004) ao elucidarem que, na medida em que a GP evoluiu, passou a haver um maior enfoque sobre os aspectos comportamentais e as competências gerenciais dos gerentes de projeto com vistas a obter sucesso.

Alguns autores como Ofori (2013) argumentam que a atenção aos detalhes, juntamente com a participação dos principais interessados e a documentação adequada em cada fase, garante o sucesso e qualidade do projeto. Todavia, esses pontos podem estimular o sucesso, mas é difícil de obter garantias em uma seara tão complexa como a GP. Mais do que isso, Han et al. (2012) lembram que a própria definição de sucesso do projeto é uma questão elusiva e que a falta de uma definição consensual para isso tem sido a razão para não definir e avaliar o sucesso em muitas situações. $\mathrm{Na}$ verdade, eles questionam até se seria necessário ou não definir o sucesso. Não obstante, esses autores revelam a importância de identificar os FCS, como um passo no sentido de aumentar a probabilidade de sucesso dos projetos no futuro, definindo como fatores de sucesso aqueles que influenciam, constituem ou determinam o sucesso de um projeto.

Sem embargo, os supramencionados autores reconhecem que é possível fazer uma distinção entre sucesso da GP e sucesso do projeto (Han et al., 2012), sendo o primeiro associado ao sucesso da atuação direta do gerente de projetos ao aplicar as ferramentas dessa disciplina frente às restrições de qualquer projeto, composta por escopo, prazo e custo. Nesse sentido, um projeto bem-sucedido seria aquele cujo escopo inicial foi cumprido, que foi no prazo estipulado e que teve os custos decorrentes da sua execução dentro do orçado. Considerando os conflitos potenciais entre a otimização dessas restrições, o desafio da GP consiste em administrar esse trade off de forma a maximizar os benefícios decorrentes da realização do projeto, buscando uma alta eficiência na aplicação dos recursos disponíveis durante a execução do projeto. Por outro lado, o segundo aspecto se refere aos objetivos e benefícios previstos pelo projeto para a organização como um todo, voltando-se para a eficácia no alcance dos objetivos previstos para o projeto (Morioka \& Carvalho, 2014).

Shenhar et al. (1997) identificaram que o problema não é a definição de sucesso de projeto, mas o fato de que as pessoas têm percepções diferentes sobre o sucesso, e esta percepção varia no tempo. Assim, eles propõem uma avaliação em quatro dimensões:

- Dimensão 1: Eficiência do projeto, que avalia o grau de eficiência na GP, analisando se este terminou no prazo certo e dentro do orçamento. Algumas instituições podem acrescentar alguns indicadores próprios de seu segmento nesse quesito, como a quantidade de alterações no produto antes de ser disponibilizado para venda, etc.

- Dimensão 2: Impacto no cliente, tendo como referência a atenção aos seus desejos e necessidades reais dos mesmos, bem como a satisfação desses com o produto e o quanto ele está propenso a pagar por uma extensão do projeto, por exemplo.

- Dimensão 3: Sucesso direto no negócio e o impacto que o projeto terá na organização considerando, por exemplo, sua participação nos lucros, quantos negócios alavancará, se aumentará a participação da empresa no mercado, etc.

- Dimensão 4: Estar preparado para o futuro, que avalia o quanto o projeto ajudou na construção da infraestrutura da organização para o futuro, possibilitando a criação de um novo mercado, uma nova linha de produtos ou uma nova tecnologia.

Uma das questões críticas para obter o sucesso consiste na aplicação dos conhecimentos das pessoas em GP - o que requer a adoção eficaz de processos apropriados (Ruuska \& Vartiainen, 2003; Olson et al., 2001; Alves et al., 2013). Em cada processo, são abordadas as entradas e saídas, suas características, como também os artefatos, técnicas e ferramentas envolvidas. A matriz ilustrada a seguir provê uma visão quantitativa da distribuição dos processos de gerenciamento de projetos pelas áreas de conhecimento.

Pela análise da Figura 1, podem-se perceber algumas características lógicas dos processos de GP: (i) que praticamente todas as áreas de conhecimento são abordadas nas atividades de planejamento (definir, estimar e planejar cada aspecto do projeto) e de monitoramento e controle (controlar). No PMI 


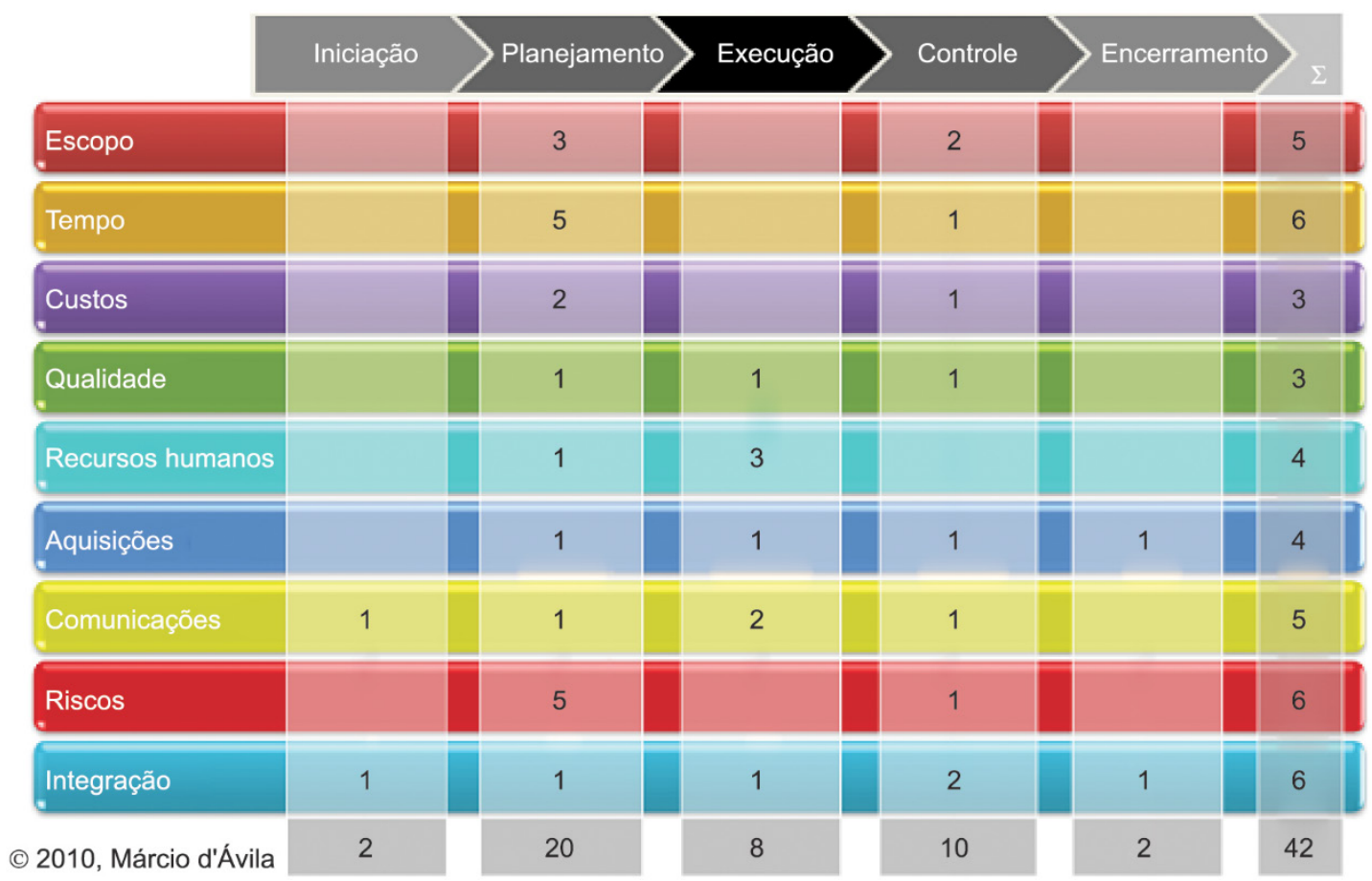

Figura 1. Matriz da Relação entre fases e elementos-chave de um Projeto. Fonte: D’Ávila (2013).

(2013), o processo de gerenciar a equipe passou ao grupo de execução, deixando apenas a área de recursos humanos (RH) sem processos no grupo de controle; (ii) que na fase de execução, os aspectos envolvidos mais ativamente são a equipe de RH, de aquisições, de comunicações e de garantia da qualidade; e, ainda, (iii) que a integração se faz presente em todos os momentos do projeto. Nessa figura, os grupos de processos representam os tipos de atividades; as áreas de conhecimento caracterizam os assuntos; e seu cruzamento induz, de forma bastante intuitiva, os respectivos verbos - definir, planejar, estimar, gerenciar, monitorar, controlar, encerrar, etc. - e substantivos que descrevem os processos de gestão relacionados. Essa constatação mostra que os conceitos e práticas que o guia reúne, organiza e formaliza, estão naturalmente presentes na essência do gerenciamento de qualquer bom projeto.

Para a gestão adequada de um projeto, o PMI (2013) indica que existem cinco áreas de especialização que as equipes que atuam na GP devem entender e usar: (i) conjunto de conhecimentos em gerenciamento de projetos; (ii) conhecimento das normas e regulamentos da área de aplicação do projeto; (iii) entendimento do ambiente do projeto (cultural, social, internacional, político e físico); (iv) conhecimento e habilidades gerenciais e (v) habilidades interpessoais.

As habilidades interpessoais incluem a comunicação eficaz, a influência sobre a organização, a liderança, a negociação e o gerenciamento de conflitos, a motivação e a capacidade de resolução de problemas.
Segundo Jordão et al. (2013), é nesse contexto que o conhecimento, ou melhor, que a gestão do conhecimento (Knowledge Management) se transforma em um valioso recurso estratégico para a vida das pessoas e das empresas na busca pela excelência humana, operacional e gerencial. Mais do que isso, autores como Alves et al. (2013) evidenciam que uma adequada identificação dos FCS junto à aplicação de práticas de gestão do conhecimento nos processos intensivos em conhecimento que compõem a gestão de projetos aumentam a probabilidade de sucesso destes. Os resultados obtidos por Vezzoni et al. (2013) também reforçam a ideia de que a comunicação eficiente, o empowerment, o gerenciamento de mudanças, o gerenciamento de requisitos, a preparação para enfrentar riscos e o suporte e envolvimento da alta administração aumentam a probabilidade dos projetos atingirem o sucesso.

A Figura 2 apresenta o hexágono da excelência, ou seja, as seis áreas nas quais as organizações consideradas excelentes em gestão de projetos superam a concorrência, começando pela excelência comportamental.

Segundo Kerzner (2002), os processos integrados se referem à integração da gerência de projetos com os outros processos administrativos. A cultura deve sustentar os valores básicos da gerência de projetos: a cooperação, o trabalho em equipe, a confiança e a comunicações mais eficientes, além de estimular a capacidade de mudança e adaptação. $\mathrm{O}$ fator suporte gerencial deve ser visível e ativo, em que a gerência 


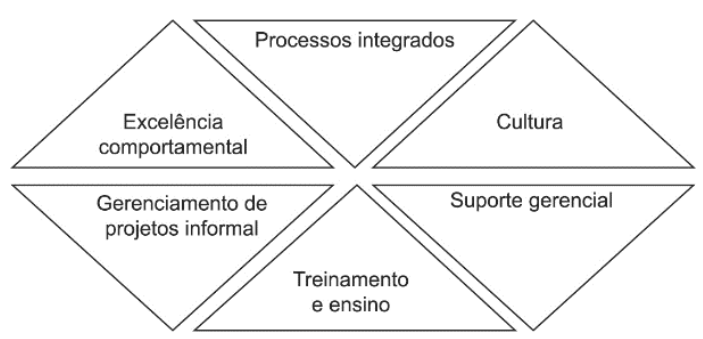

Figura 2. Os seis componentes da excelência. Fonte: Kerzner (2002).

argumenta e mostra a importância da GP e promove ações cotidianas que incentivem e fomentem essa cultura. O treinamento e desenvolvimento (ensino) são necessários para dar sustentação às atividades de GP, pois a qualidade da capacitação, em conjunto com o apoio dos executivos e formas de gestão informal, ajuda a estimular a promoção de melhorias nos demais aspectos, assim como fomentar o sucesso na GP e, por conseguinte, a excelência.

\section{Metodologia}

A pesquisa descrita neste artigo consiste em um estudo de caso de natureza qualitativa (baseada em entrevistas e observação participante) e quantitativa (baseada em técnicas estatísticas para descrição da realidade investigada) e de abordagem descritiva (Cooper \& Schindler, 2006; George \& Bennett, 2005). Ressalta-se que, embora os resultados encontrados não possam ser indiscriminadamente generalizáveis, pois a análise limita-se a um único estudo de caso, Eisenhardt (1989) ressalta a relevância desse tipo de pesquisa, lembrando que o mesmo facilita a construção de novas teorias e modelos. Consoante, Yin (1984) postula que o estudo de caso consiste em uma análise intensiva de uma situação particular investigada sem interferência significativa do pesquisador. Nesse caso, tomou-se como unidade de análise uma empresa latino-americana de grande porte de classe mundial e como unidade de observação uma equipe de projetos dessa empresa - na qual foi realizado um estudo de caso, permitindo investigar a percepção dos empregados dos diversos níveis hierárquicos sobre o tema, em linha com as proposições de Yaraghi \& Langhe (2011), Alves et al. (2013), Hwang \& Lim (2013) e Morioka \& Carvalho (2014) - que sugerem ser esta abordagem suficientemente sensível para captar a complexidade inerente ao estudo dos FCS em GP.

Dentre as várias fontes de evidências existentes em um estudo de caso de natureza quali-quantitativa, priorizou-se como fonte primária a realização de entrevistas pessoais, apoiadas em um questionário com questões estruturadas (Eisenhardt, 1989). Dentre 27 pessoas da equipe estudada, foi selecionada, de forma aleatória, uma amostra de 19 pessoas. A coleta de dados que foi feita por meio da aplicação de um questionário, cujo roteiro foi dividido em duas seções: informações gerais e indicadores relacionados a FCS (possíveis problemas) enfrentados pela equipe no desenvolvimento dos projetos da empresa. O roteiro baseou-se na utilização de uma escala do tipo Likert de grau 7. A escolha de 7 graus se deu tendo em vista que a média não fosse coincidente com a mediana e permitisse uma melhor qualidade dos dados. $\mathrm{O}$ significado da comunicação linguística contido nas respostas foi discutido através da técnica de análise de conteúdo, como indicado por Bardin (2004).

O roteiro de pesquisa foi composto por 07 variáveis desmembradas em 30 questões, baseando-se em variáveis extraídas da literatura referentes a resultados empíricos de estudos anteriores sobre o tema. Além disso, houve um esforço para refinar a validade dos indicadores por meio de entrevistas com empregados, gestores, diretores e especialistas em gestão de projetos. Esses indicadores contêm informações sobre: a) definição dos objetivos; b) envolvimento do cliente; c) habilidades do gerente de projetos; d) planejamento; e) custo (esta foi apontada como uma das variáveis mais sensíveis ao sucesso do projeto); f) comunicação; e g) técnica.

Para a análise dos resultados calculou-se a mediana (o número posicionado no centro de um conjunto numérico); a moda (o valor que ocorre com mais frequência numa matriz ou intervalo de dados); a média (valor esperado); e o desvio-padrão (medida do grau de dispersão dos valores em relação ao valor médio). Posteriormente, visando maior nível de profundidade e detalhamento da análise, foi realizada uma abordagem quantitativa para estabelecer o Ranking Médio (RM). Realizou-se a verificação quanto à criticidade dos FCS analisados através das 22 proposições avaliadas, com a obtenção do RM da pontuação atribuída às respostas, relacionando à frequência das respostas dos funcionários que fizeram tal atribuição, foi calculado o Ranking Médio, conforme proposto por Oliveira (2005) da seguinte forma (Equações 1 e 2):

$$
\begin{gathered}
\text { Média Ponderada (MP) }=\sum(f i . V i) \\
\text { Logo o RM }=\text { MP / (NS) }
\end{gathered}
$$

Onde:

$f i=$ frequência observada de cada resposta para cada item

$V i=$ valor de cada resposta

$\mathrm{NS}=\mathrm{n}^{\mathrm{o}}$. de funcionários

Para aumentar a validade interna do estudo, procurou-se agregar informações coletadas em outras fontes de evidência. Esse processo é conhecido como triangulação (Jick, 1979). Na triangulação, realizou-se uma análise intergrupos e intragrupos, visando construir uma cadeia de evidências e dar maior robustez ao estudo, seguindo as recomendações de Eisenhardt 
(1989) - que descreveu as formas de construção de teorias a partir de estudos de caso. Assim, sempre que possível, as informações advindas de uma fonte foram confrontadas com as de outras para confirmá-las e validá-las ou então refutá-las. Salienta-se que, no presente trabalho, esse procedimento iniciou-se com os próprios questionários, cujas respostas foram confrontadas com entrevistas com pessoas de diferentes níveis gerenciais (da direção à operação), sendo ouvidas diferentes pessoas sobre um mesmo tópico. Paralelamente, foram realizadas visitas à fábrica e ao escritório da empresa para apreender, de maneira mais detalhada, as especificidades do negócio dessa empresa, além da experiência de um dos autores na empresa (observação participante). Em um momento posterior, a triangulação envolveu a análise de folhetos informativos, de webpages, do sítio eletrônico da empresa, do manual da qualidade (MQ), de procedimentos e políticas corporativas, de alguns documentos internos e de notícias publicadas sobre a empresa nos periódicos da época (análise documental). Por motivo de parcimônia, os resultados são apresentados ao longo do texto de forma já triangulada, ou seja, sem segregação explícita dos resultados por fonte de dados. Analisaram-se também as notícias publicadas no jornal interno da empresa, as tabelas de indicadores dos últimos cinco anos (até 2010) e as informações obtidas em conversas informais (até julho de 2012), além de contatos posteriores às entrevistas, com o propósito de complementar dados e de esclarecer as dúvidas existentes.

\section{Apresentação e análise do caso}

A empresa Alpha é a maior empresa privada na América Latina, a segunda maior mineradora diversificada do mundo e a maior das Américas em valor de mercado, assim como uma das 30 maiores companhias públicas negociadas no mundo. Atuando por meio de escritórios, operações, explorações e joint ventures emprega, atualmente, mais de 115 mil pessoas (direta e indiretamente). Sendo a maior produtora e exportadora mundial do produto que fabrica e uma das 25 maiores geradoras de valor sustentável aos acionistas no mundo - devido ao seu significativo desempenho ao longo dos últimos 10 anos. Essa é uma empresa latino-americana de grande porte de classe mundial que atua em 38 países dos cinco continentes e tem capitalização de mercado de aproximadamente US\$ 170 bilhões, com receita operacional superior a US\$ 40 bilhões e cerca de 500 mil acionistas em todos os continentes, possuindo escritórios comerciais em diversos países e uma participação crescente no mercado internacional.

O principal objetivo da empresa estudada é maximizar valor para os acionistas. As atividades dela são guiadas por uma política de transparência, respeito ao direito dos acionistas, proteção ao meio ambiente, desenvolvimento dos empregados e melhoria da qualidade de vida nas comunidades onde opera. A missão da empresa Alpha é transformar recursos minerais em riqueza e desenvolvimento sustentável, e sua visão é ser a maior empresa de mineração do mundo e superar os padrões consagrados de excelência em pesquisa, desenvolvimento, implantação de projetos e operação de negócios. Tendo como base a premissa de que a GP pode ajudar a organização a atingir seus objetivos estratégicos, a atividade de projetos, nessa empresa, envolve as mais diversas áreas, processos, funções e atividades em todos os níveis hierárquicos. A empresa Alpha possui uma longa e bem-sucedida experiência no desenvolvimento de projetos, disciplina na alocação de capital e sólida posição financeira, com sólidas oportunidades de crescimento e melhorias. Importantes investimentos têm sido realizados no aprimoramento tecnológico dos processos produtivos e dos sistemas de controle, bem como no aperfeiçoamento dos procedimentos operacionais. Os projetos são considerados atividades fundamentais na empresa, da área estratégica à área operacional, a fim de administrar as oportunidades (inovação, mercado, concorrência, novas tecnologias, posicionamento, objetivos) e, assim, ajudar a alcançar os resultados planejados.

Considerando o ambiente que essa empresa está inserida, observou-se que alguns fatores críticos ou exigências para o sucesso se destacaram como: a agilidade, o poder de inovar de forma rápida e eficiente, a capacidade de adaptação e o potencial de aprimoramento contínuo com grandes restrições de recursos, sendo a GP uma atividade de importância singular no desenvolvimento de alguns negócios e no alcance de resultados desses negócios. O Estudo de Caso foi realizado em uma equipe de técnicos de processo de uma unidade industrial (onde um dos autores trabalhava na área de engenharia e teve a oportunidade de participar de projetos de forma direta e indireta) que se responsabilizava pela qualidade dos produtos gerados na usina, pelo ritmo da produção e pela produtividade dos equipamentos, fazendo uma interface com diversas áreas internas e externas da empresa (mecânica, elétrica, automação, fornecedores) - a fim de garantir o melhor desempenho para a Usina e mitigar os riscos dos processos como proposto por Wu \& Chen (2006) e Han et al. (2012).

Tendo com base a necessidade de processos de melhorias, os gestores reúnem-se com os técnicos e elaboram os projetos e planos. Porém, como diariamente surgem muitos imprevistos na área, dentre outras dificuldades, os cronogramas nem sempre são cumpridos e muitas vezes alguns projetos são abandonados. Dessa forma, houve a necessidade de entender a percepção sobre os FCS na GP para os funcionários de diferentes níveis hierárquicos. $\mathrm{Na}$ Tabela 1 apresenta-se inicialmente a mensuração dos 
Tabela 1. Fatores críticos

\begin{tabular}{|c|c|c|c|c|c|c|c|c|c|c|c|c|c|c|c|c|c|c|c|c|c|c|}
\hline Indicadores & 1 & 2 & 3 & 4 & 5 & 6 & 7 & 8 & 9 & 10 & 11 & 12 & 13 & 14 & 15 & 16 & 17 & 18 & 19 & 20 & 21 & 22 \\
\hline Média & 1,8 & 2,73 & 2,93 & 1,87 & 1,6 & 3,53 & 2,27 & 2 & 3,33 & 4 & 3,2 & 3,2 & 3,6 & 3,67 & 2,73 & 2,73 & 2,93 & 2,2 & 3,67 & 3,67 & 3,27 & 2,87 \\
\hline Desvio-padrão & 1,9 & 1,98 & 1,79 & 1,51 & 1,12 & 1,36 & 1,94 & 1,73 & 1,76 & 1,46 & 1,9 & 1,52 & 1,8 & 1,95 & 2,05 & 1,98 & 1,62 & 1,74 & 0,98 & 1,8 & 1,71 & 1,73 \\
\hline Moda & 0 & 4 & 3 & 3 & 1 & 5 & 0 & 0 & 3 & 5 & 5 & 3 & 3 & 3 & 1 & 0 & 1 & 3 & 3 & 3 & 3 & 1 \\
\hline Mediana & 2 & 3 & 3 & 2 & 1 & 4 & 2 & 2 & 3 & 4 & 3 & 3 & 3 & 3 & 2 & 3 & 3 & 2 & 3 & 4 & 3 & 3 \\
\hline
\end{tabular}

Fonte: Elaborado pelos autores com base nos dados da pesquisa.

22 indicadores considerados críticos. Os resultados foram inicialmente agrupados, independentemente da formação e função dos funcionários.

A partir da análise dos dados, foi possível observar que os itens $1,2,4,5,7,815,16,18$ e 22 foram aqueles que obtiveram uma média na avaliação abaixo de 2,9 pontos, sendo, por isso, considerados muito críticos. O número 2,9, nesse conjunto de dados, foi escolhido como parâmetro de comparação por ser a média da pontuação recebida nos 22 itens. Os indicadores considerados mais críticos pela equipe estudada e que, na visão dos entrevistados, devem ser tratados e analisados com mais cuidado na tentativa de melhorar a GP na empresa foram: definição dos objetivos, envolvimento dos clientes, definição do planejamento, capacidade de seguir o planejamento, comunicação entre os integrantes, aquisição de materiais, feedback do trabalho, suporte gerencial, gerenciamento dos riscos e gerenciamento dos gastos.

Já os itens que na, média geral, obtiveram as menores pontuações foram: conhecimento gerencial exigido, conhecimento técnico exigido, inovações desenvolvidas, aprendizagem, treinamento oferecido, arquivos para gestão do conhecimento. Logo, foi possível observar que a equipe analisada dá pouca importância para o conhecimento e inovações geradas pelos projetos. Visando um melhor entendimento de tais questões, buscou-se segregar os dados gerados pelas entrevistas em grupos com opiniões semelhantes ( $c f$. Gráficos 1, 2 e 3). Como Ruuska \& Vartiainen (2003) e Han et al. (2012) já haviam observado, nesse caso, também se percebeu a complexidade e o desafio em minimizar os impactos desses fatores críticos de sucesso. Dessa forma, verificou-se que a solução do problema de gestão dos FCS vai além do simples treinamento de funcionários para utilização de sistemas ou softwares de GP, como observado por Vezzoni et al. (2013). Os resultados desse estudo indicaram que é fundamental a educação e/ou aculturamento. Alguns colaboradores afirmaram que essas questões devem ter precedência sobre o treinamento (convencional), de modo a "pavimentar o caminho sobre o qual a absorção do conhecimento prático se dará".

Ao aplicar o questionário, esperavam-se três tendências de fatores críticos: a primeira dos gestores, a segunda dos técnicos de nível médio e técnicos que cursam curso superior e a terceira dos técnicos que já concluíram o ensino superior. Porém, ao analisar os

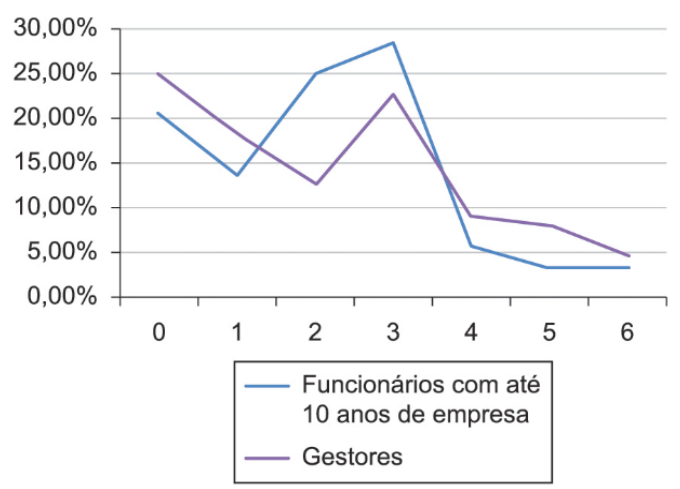

Gráfico 1. Relação entre Fatores Críticos para Gestores e Funcionários com até 10 anos de empresa. Fonte: elaborado pelos autores com base nos dados da pesquisa.

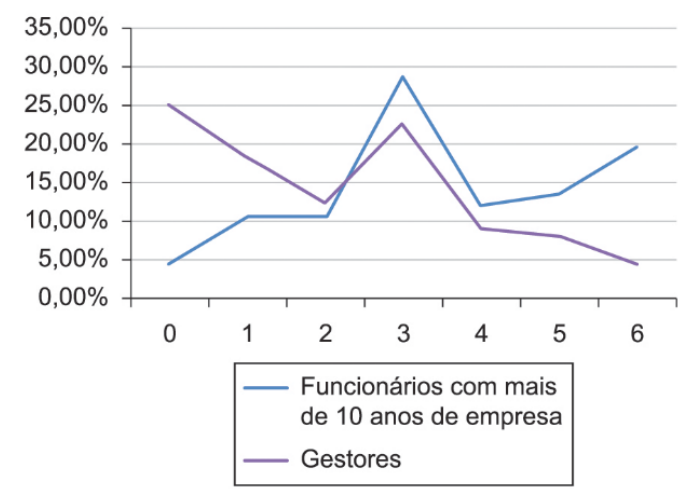

Gráfico 2. Relação entre Fatores Críticos para Gestores e Funcionários com mais de 10 anos de empresa. Fonte: elaborado pelos autores com base nos dados da pesquisa.

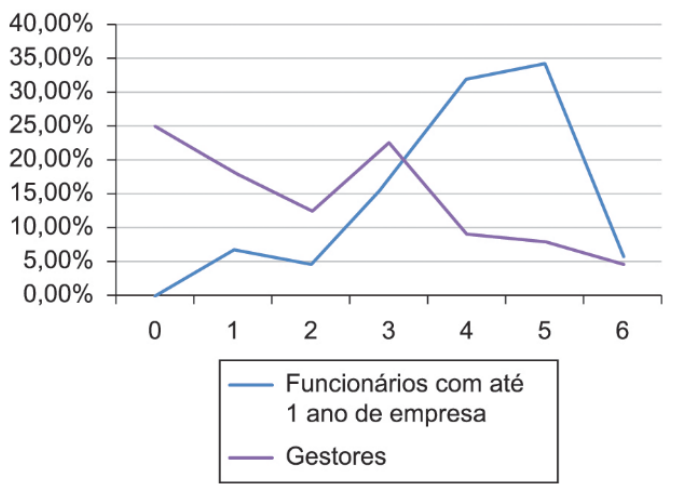

Gráfico 3. Relação entre Fatores Críticos para Gestores e Funcionários com até 1 ano de empresa. Fonte: elaborado pelos autores com base nos dados da pesquisa. 
resultados em um segundo nível de análise, observou-se que os dados indicam que, independentemente da formação acadêmica, foi possível identificar quatro grupos bem distintos:

\section{Gestores.}

2. Técnicos com até 10 anos de empresa (que seguem a tendência dos gestores).

3. Técnicos entre 10 e 30 anos de empresa (que têm um perfil mais conservador).

4. Funcionários com menos de 1 ano de empresa (operador, estagiários e engenheiro).

Dessa forma, com os dados disponíveis foi feita uma relação entre o grupo dos gestores e os demais grupos em relação aos níveis de criticidade $(0,1,2$, $3,4,5,6)$. Esta relação pode ser vista no Gráfico 1.

Pode-se perceber pelo gráfico que os gestores consideraram $25 \%$ dos indicadores listados como muito críticos (igual a 0), e pouco mais de $20 \%$ de criticidade razoável (igual a 3), enquanto menos de $5 \%$ foram considerados pouco críticos (igual a 6 ). Os funcionários com até 10 anos de empresa seguiram a mesma tendência, pois consideraram mais de $20 \%$ dos indicadores muito críticos e menos de $5 \%$ pouco críticos, e os demais, de forma geral, se mantiveram nas faixas 2 e 3 . No Gráfico 2 apresenta-se a relação para gestores e funcionários com mais de 10 anos de empresa.

Já os funcionários com mais de 10 anos de empresa julgaram que $20 \%$ dos indicadores listados são considerados pouco críticos (igual a 6) e menos de $5 \%$ são considerados muito críticos, o que diferencia da opinião dos gestores. Já os itens considerados razoavelmente críticos (igual a 3 ) em ambos os casos ficaram entre 20 e $30 \%$. Pode-se perceber que estes funcionários conhecem bem o processo, os projetos, possuem muitas experiências, porém têm um perfil diferenciado, ou seja, consideram grande parte dos fatores de criticidade pouco significativos.

Alguns pesquisadores que também trabalharam com pesquisas relacionadas aos fatores críticos do gerenciamento de projetos em outros segmentos e obtiveram resultados semelhantes aos de tal estudo. Coutinho (2009), por exemplo, identificou que nas empresas de engenharia consultiva há a aversão as mudanças, pois os funcionários já adaptados aos padrões de gerenciamento existentes nas empresas tornam-se resistentes a adoção de novas técnicas e ferramentas, presentes em um corpo de conhecimentos como o PMI (2013).

Os obstáculos ligados à resistência às mudanças exercidas, por parte dos envolvidos na gestão do projeto, estão diretamente associados à falta de preparo e treinamento e também à falta de ferramentas de gestão. Esses resultados em conjunto indicam que os funcionários mais antigos, embora tenham uma visão mais aguçada da realidade da empresa, são mais avessos à s mudanças. Já os dados relativos a Gestores e Funcionários com até 1 ano de empresa estão no Gráfico 3.

Como pode ser visto, os funcionários novatos não consideraram nenhum indicador como sendo muito crítico (igual a 0 ) e apenas $6 \%$ com criticidade significativa (igual a 1). Na maioria das vezes, julgaram $66 \%$ dos itens com a criticidade baixa (igual a 4 e 5 ).

Ao analisar e relacionar as respostas dos funcionários que têm menos de 1 ano de empresa com as dos demais funcionários, notou-se que a pontuação sugerida por eles é bem distinta em relação aos FCS na GP - possivelmente pela pequena experiência no segmento. Dessa forma, ao compilar os dados na Tabela 2, os autores optaram por separar este grupo dos demais. Assim, apresentam-se na Tabela 2 os resultados obtidos a partir da verificação das informações sobre os FCS em projetos na equipe estudada segmentada nos quatro níveis. Os dados indicam baixa variação nas respostas em torno da média quando se exclui o grupo de funcionários com até 1 ano de empresa e alta variação quando se considera este grupo.

A Tabela 2 mostra o ranking geral das 4 categorias estudadas, bem como o ranking geral com a média destas 4 categorias e o ranking geral (com exceção dos novatos) da média de 3 categorias, além de mostrar o desvio-padrão de duas formas diferentes: considerando ou não os novatos.

Ao final da tabela, há o somatório do número de itens que obtiveram o ranking médio menor ou igual a 2 (considerados muito críticos). Dessa forma, verificou-se que os gestores consideram 11 dos 22 itens como muito críticos, enquanto a categoria dos novatos não considera nenhum destes itens muito críticos. Da mesma forma, foi feito o somatório de itens com alto desvio-padrão e novamente notou-se que não há coerência a compilação dos dados dos novatos. Considerando o grupo quatro, observou-se um desvio-padrão de 1,09, com 16 dos 22 itens com o desvio-padrão maior ou igual a 1. Desconsiderando este grupo, a média caiu para 0,72 e o número de itens que tiveram o desvio-padrão maior ou igual a 1 caiu para 5 .

Após o cálculo do RM e do desvio-padrão para os 4 grupos analisados, foi observado que, como na análise das escalas anteriormente feita, o grupo composto por funcionários com menos de 1 ano de empresa (grupo 4) estava fora da tendência dos demais grupos. Dessa forma, foi desconsiderado este quarto grupo nas demais análises, por não apresentar uma contribuição significativa para o entendimento do tema (nesse caso específico). Outrossim, recomenda-se que para uma próxima aplicação deste questionário seja avaliada criticamente a capacidade informativa 
Tabela 2. Ranking médio e Desvio-padrão de cada indicador crítico.

\begin{tabular}{|c|c|c|c|c|c|c|c|c|}
\hline & \multicolumn{6}{|c|}{ Ranking médio } & \multicolumn{2}{|c|}{ Desv. Padrão } \\
\hline & Gestores & $\begin{array}{l}\text { Mais de } \\
10 \text { anos }\end{array}$ & $\begin{array}{c}\text { Até } 10 \\
\text { anos }\end{array}$ & $\begin{array}{c}\text { Menos de } \\
1 \text { ano }\end{array}$ & Geral & $\begin{array}{c}\text { Geral } \\
\text { (exceção de } \\
\text { novatos) }\end{array}$ & Geral & $\begin{array}{c}\text { Geral } \\
\text { (exceção de } \\
\text { novatos) }\end{array}$ \\
\hline 1 & 0,50 & 2,33 & 0,50 & 4,00 & 1,83 & 1,11 & 1,68 & 1,06 \\
\hline 2 & 2,25 & 1,67 & 1,25 & 4,00 & 2,29 & 1,72 & 1,21 & 0,50 \\
\hline 3 & 2,75 & 3,33 & 1,50 & 4,25 & 2,96 & 2,53 & 1,15 & 0,94 \\
\hline 4 & 0,25 & 2,67 & 1,75 & 3,00 & 1,92 & 1,56 & 1,23 & 1,22 \\
\hline 5 & 0,50 & 1,67 & 1,75 & 2,50 & 1,60 & 1,31 & 0,83 & 0,70 \\
\hline 6 & 3,00 & 3,33 & 2,75 & 5,00 & 3,52 & 3,03 & 1,01 & 0,29 \\
\hline 7 & 1,00 & 2,33 & 0,50 & 3,75 & 1,90 & 1,28 & 1,46 & 0,95 \\
\hline 8 & 0,75 & 1,33 & 2,25 & 3,50 & 1,96 & 1,44 & 1,20 & 0,76 \\
\hline 9 & 2,50 & 2,33 & 3,00 & 3,75 & 2,90 & 2,61 & 0,64 & 0,35 \\
\hline 10 & 3,50 & 3,33 & 3,25 & 4,50 & 3,65 & 3,36 & 0,58 & 0,13 \\
\hline 11 & 2,00 & 3,33 & 1,50 & 4,75 & 2,90 & 2,28 & 1,46 & 0,95 \\
\hline 12 & 1,75 & 3,67 & 2,50 & 4,75 & 3,17 & 2,64 & 1,32 & 0,97 \\
\hline 13 & 3,50 & 3,33 & 3,50 & 4,00 & 3,58 & 3,44 & 0,29 & 0,10 \\
\hline 14 & 4,25 & 3,00 & 2,75 & 4,50 & 3,63 & 3,33 & 0,88 & 0,80 \\
\hline 15 & 1,75 & 2,00 & 1,00 & 4,50 & 2,31 & 1,58 & 1,52 & 0,52 \\
\hline 16 & 1,75 & 1,67 & 1,50 & 4,50 & 2,31 & 1,58 & 1,43 & 0,13 \\
\hline 17 & 2,50 & 1,67 & 2,50 & 3,50 & 2,54 & 2,22 & 0,75 & 0,48 \\
\hline 18 & 1,00 & 3,67 & 1,50 & 3,00 & 2,29 & 2,06 & 1,25 & 1,42 \\
\hline 19 & 4,00 & 3,33 & 3,00 & 4,25 & 3,65 & 3,44 & 0,58 & 0,51 \\
\hline 20 & 3,25 & 1,00 & 2,25 & 4,50 & 2,75 & 2,17 & 1,49 & 1,13 \\
\hline 21 & 1,75 & 2,33 & 3,75 & 4,00 & 2,96 & 2,61 & 1,09 & 1,03 \\
\hline 22 & 2,75 & 1,00 & 1,75 & 3,25 & 2,19 & 1,83 & 1,01 & 0,88 \\
\hline Média & 2,15 & 2,47 & 2,09 & 3,99 & 2,67 & 2,24 & 1,09 & 0,72 \\
\hline \multirow{2}{*}{$\begin{array}{l}\text { Número de } \\
\text { Itens }\end{array}$} & 11,00 & 8,00 & 11,00 & 0,00 & 5,00 & 9,00 & 16,00 & 5,00 \\
\hline & \multicolumn{6}{|c|}{ Com $\mathrm{RM}$ menor ou $=$ a 2 , ou seja, muito críticos } & \multicolumn{2}{|c|}{$\mathrm{DP}$ maior ou $=\mathrm{a} 1$} \\
\hline
\end{tabular}

Fonte: Elaborado pelos autores com base nos dados da pesquisa.

dos funcionários que estejam a menos de 1 ano na equipe para verificar se ele deveria ou não ser um respondente potencial. O Quadro 1 mostra uma síntese dos resultados observados no estudo.

Considerando o Ranking médio dos questionários dos gestores para permitir uma triangulação das informações entre os grupos, observou-se que os 7 itens considerados mais críticos são, respectivamente: 4 - Definição do Planejamento; 1 - Definição dos objetivos; 5 - Seguir planejamento; 8 - Aquisição de materiais; 7 - Comunicação entre integrantes; 18 - gerenciamento dos riscos; 12 - Resultado obtido.

Para os funcionários com mais de 10 anos os 7 itens mais críticos são, respectivamente: 20 - Equipe selecionada; 22 - Gerenciamento dos gastos; 8 -Aquisição de materiais; 2 - Envolvimento do cliente; 5 - Seguir planejamento; 16 - Suporte gerencial; 17 - Controles ao longo do projeto.

Para os funcionários com até 10 anos de empresa, os 7 itens mais críticos são, respectivamente: 1 -Definição dos objetivos; 7 - Comunicação entre integrantes; 15 - Feedback do trabalho; 2 - Envolvimento do cliente; 3 - Habilidades do gerente de projetos; 11 - Qualidade do trabalho; 16 - Suporte gerencial.

Vale ressaltar que os indicadores de suporte gerencial e envolvimento do cliente estiveram entre os primeiros do ranking dos funcionários que não gerenciam projetos (nos dois segundos grupos analisados), e as habilidades do gerente de projetos foi outro item de destaque pelo terceiro grupo estudado. Segundo Carvalho (1997), suporte gerencial refere-se à autoridade e ao poder existente na organização para gerenciar os recursos do projeto. Os interessados, considerando-se este fator, em geral, estimulam o desenvolvimento de projetos e uso da abordagem de gerenciamento de projetos.

Esta é uma informação importante de ser divulgada entre os gerentes de projetos para que as devidas medidas de melhoria possam ser tomadas, como investir em treinamento na área de GP e aumentar o 
Quadro 1. Principais fatores críticos de sucesso por grupo de funcionários.

\begin{tabular}{|l|l|l|}
\hline \multicolumn{3}{|c|}{ Fatores de sucesso por nível de criticidade - considerando o ranking médio dos questionários } \\
\hline Gerentes & Funcionários Seniores (+ de 10 anos) & Funcionários até 10 anos \\
\hline 4- definição do planejamento & 20- equipe selecionada & 1 - definição dos objetivos \\
\hline 1- definição dos objetivos & 22- gerenciamento dos gastos & 7- comunicação entre integrantes \\
\hline 5- seguir planejamento & 8- aquisição de materiais & 15- feedback do trabalho \\
\hline 8- aquisição de materiais & 2- envolvimento do cliente & 2- envolvimento do cliente \\
\hline 7- comunicação entre integrantes & 5- seguir planejamento & 3- habilidades do gerente \\
\hline 18- gerenciamento dos riscos & 16- suporte gerencial & 11- qualidade do trabalho \\
\hline 12- resultado obtido & 17 - controles ao longo do projeto & 16- suporte gerencial \\
\hline
\end{tabular}

Fonte: Elaborado pelos autores com base nos dados da pesquisa.

envolvimento e o suporte às equipes que desenvolvem os projetos.

Vale ressaltar que os itens definir e seguir planejamento, bem como definir o objetivo obtiveram as menores pontuações na classificação geral, sendo considerados os itens de maior criticidade pela equipe. Segundo vários autores como Kerzner (1992) e Premkumar \& King (1992), a inexistência do planejamento implica fracasso certo do projeto. Segundo os funcionários de até dez anos e os funcionários seniores, o planejamento em si é justificado pela existência, verificada, de experiências frustradas de implementação de programas de gerência de projetos. No caso estudado, a finalidade do planejamento do projeto era criar um plano do projeto com cronograma de tempo, recurso e pontos de risco, que um gestor de projeto possa usar para acompanhar o progresso de sua equipe, em linha com as premissas de Charvat (2003), Yaraghi \& Langhe (2011), Hwang \& Lim (2013) e Han et al. (2012). Dessa forma, com a melhor estruturação do planejamento e dos treinamentos gerenciais, tais itens que foram considerados críticos pela equipe de GP conseguiram ser mais bem administrados em linha com os resultados de Alves et al. (2013) e Vezzoni et al. (2013).

Outro item de destaque observado na pesquisa foi relacionado à área de comunicações, como já destacada por Ruuska \& Vartiainen (2003) e Vezzoni et al. (2013), que argumentam que a comunicação entre os stakeholders de um projeto é um FCS que, se bem gerenciado, aumentam a probabilidade dos projetos atingirem o sucesso. Corrobora esta visão Han et al. (2012), ressaltando que a comunicação é a alma da GP e que o vácuo criado pela falha de comunicação rapidamente será preenchido por rumores e interpretações errôneas. No contexto brasileiro, um estudo empírico desenvolvido por Rabechini et al. (2002) com gerentes de projeto também já havia identificado a área de comunicação como um dos FCS em projetos.

Foi possível perceber que alguns funcionários consideram fundamental que o gestor esteja atento à dificuldade de comunicação entre a equipe, devido ao emprego de termos técnicos por parte de membros que para uns são comuns, mas que para outros são de difícil entendimento. Outro ponto importante verificado consiste no foco no objetivo final do projeto, buscando a sinergia do trabalho em grupo, evitando a busca por ganhos pessoais que geram conflitos destrutivos para a equipe e para o projeto. Em linha com as observações de Morioka \& Carvalho (2014), os gestores e funcionários devem buscar maximizar a eficiência na aplicação dos recursos disponíveis durante a execução do projeto e eficácia no alcance dos objetivos previstos.

Em um terceiro nível de análise, a triangulação das informações permitiu observar que há pessoas com perfis e tempo de empresa diferente. A empatia é fundamental para entender o que se passa com o liderado e, a partir daí, poder ajudá-lo ou direcioná-lo ao alinhamento com os objetivos do projeto e da empresa. Na visão dos mais novos na empresa, ajudar os funcionários é um ponto fundamental para que o gerente obtenha dele confiança e comprometimento com o projeto. Podemos acrescentar o relacionamento entre as áreas funcionais da empresa, como apontado por Olson et al. (2001), como um FCS importante para que o gerente de projeto possa minimizar os conflitos existentes entre os objetivos do projeto e da operação da organização.

Observou-se que a maioria dos trabalhos em equipe foi caracterizada pelos respondentes por conflitos de opiniões e ideias. Essa divergência pode ser positiva até o momento em que o foco das discussões não foge da busca de alcançar o objetivo principal que é o sucesso do projeto, como bem evidenciam Shenhar et al. (1997) ao postularem que o problema não é a definição de sucesso de projeto, mas as diferentes percepções das pessoas sobre isso. O próprio PMI (2013) reconhece a questão dos recursos humanos como um dos dez processos centrais na GP, ressaltando que habilidades interpessoais colaboram para o sucesso de projetos. Cabe, portanto, ao gerente do projeto (líder), administrar os conflitos, fazendo com que o projeto se beneficie das discussões e dos diferentes pontos de vista, evitando que os conflitos gerem perda de produtividade e um 
ambiente desconfortável. Assim, como observado por Vezzoni et al. (2013), a comunicação eficiente, o empowerment, o gerenciamento de mudanças, o suporte e o envolvimento da alta administração aumentam a probabilidade dos projetos atingirem o sucesso. Nesse sentido, outra informação que vale ser ressaltada é que, segundo os gestores, os indicadores considerados menos críticos foram os que envolvem a aprendizagem, os conhecimentos e a habilidade deles próprios - o que impactou negativamente na GP, confirmando, em parte, as evidências de Alves et al. (2013), que perceberam que a identificação dos FCS associadas a práticas de gestão do conhecimento, aumentam a probabilidade de sucesso dos projetos. Observou-se que $80 \%$ dos gestores dessa equipe são engenheiros, o que segue a tendência do mercado segundo uma recente matéria publicada na revista Época Negócios (Campos, 2014 ), realizada com os líderes das 120 maiores empresas do Brasil, que mostra que $48,3 \%$ dos presidentes de empresas, no ano de 2014, haviam estudado engenharia. Vallabbaneni (2002) cita em seu artigo que é possível que bons engenheiros técnicos tornem-se ótimos gerentes ou homens de negócio, porém, para isso, é preciso que eles estejam dispostos a serem treinados e a adquirirem novos conhecimentos através de muito estudo complementar.

Segundo Vallabbaneni (2002), os cursos de MBA (Master Business Administration) são ótimos exemplos e caminhos para que um engenheiro alcance tal posição na empresa. Outro ponto importante apontado por esse autor, e coadunado pelos funcionários com até dez anos, é que a empresa deveria considerar, na escolha de um gerente de projetos, o fato de que tempo de serviço e idade não são sinônimos de maturidade em gestão; e que experiência técnica não basta a um gerente, sendo, às vezes, prejudicial, pois pode ser que o gerente se prenda a questões técnicas (como observado) e se esqueça de alguns fatores críticos do gerenciamento.

Dessa forma, tendo como premissa a ideia de que para uma eficaz GP é fundamental que o gestor do projeto seja um profissional capacitado e que, muitas vezes, esse trabalho é desempenhado por pessoas que não estão preparadas, observou-se, parcialmente, as ideias de Alves et al. (2013) sobre a necessidade de se capacitar melhor os gerentes, investindo em formação humana e processos intensivos em conhecimento. Kerzner (2002) também percebe que, do ponto de vista dos funcionários, alguns dos obstáculos enfrentados para a implantação de procedimentos de GP são atribuídos, principalmente, ao desconhecimento pelo assunto e à falta de experiência dos profissionais envolvidos. Tendo como base a perspectiva do PMI (2013) de que a GP consiste no processo através do qual se aplicam conhecimentos, capacidades, instrumentos e técnicas às atividades do projeto, de forma a satisfazer as necessidades e expectativas dos diversos stakeholders envolvidos nele, observa-se que se tais conhecimentos não estão bem administrados e explorados, a GP pode estar falha - o que pode comprometer futuros projetos.

Assim, essas informações compiladas em conjunto indicam que os FCS em projetos devem ser observados atentamente pelos gerentes de projetos, para que se possa atuar na melhoria da GP de maneira mais assertiva, visando obter melhores resultados operacionais e gerenciais para a equipe e para a empresa. Por meio deste estudo de caso foi possível também observar que alguns técnicos da equipe estudada ficaram sem um foco definido e sobrecarregados de serviços operacionais, preocupando-se menos do que deviam com o sucesso do projeto e usando pouco tempo para os trabalhos que demandam mais tempo como as atividades de pesquisa e desenvolvimento. Vale ressaltar que a empresa oferece diversos treinamentos técnicos e de cunho ambiental para os funcionários da equipe, mas os cursos de liderança e gerenciamento são oferecidos apenas a uma pessoa: ao gerente, contradizendo as conclusões de Toledo et al. (2008), que observaram que as empresas também devem investir na formação das habilidades gerenciais e de relacionamento de seus líderes de projeto, já que sua atuação afeta positivamente o desempenho dos envolvidos na criação de novos produtos.

Vários membros apontaram que seria interessante a disseminação de tais conhecimentos, mesmo que através de reuniões e apresentações mensais, para preparar as pessoas para assumirem o papel de gerentes de projetos. Além disso, observou-se que, para que o objetivo proposto na visão da empresa seja atingido, é fundamental administrar as oportunidades (inovação, mercado, concorrência, novas tecnologias, posicionamento, objetivos) e a atuar de maneira estratégica no aprimoramento contínuo da GP.

De modo geral, observou-se que nem todos os membros percebem e analisam a importância do gerenciamento dos seus serviços por meio de boas práticas e GP. Vale ressaltar alguns aspectos marcantes sobre a GP em cada entrevista. Para um diretor, um dado fundamental para a GP consiste na qualidade dos profissionais, associada ao treinamento e à conscientização dos mesmos. Um dos gerentes de projetos reconheceu certa ambiguidade entre o que ele pensa e as decisões que teve de tomar. Ele afirmou que, apesar de a escolha da empresa ter sido no sentido de "amadurecer" o processo de desenvolvimento de software, por exemplo, a tal ponto que esse pudesse ser plenamente utilizado na fábrica, se dependesse desse gerente, ele iria preferir alocar todos os recursos integralmente no projeto. Um coordenador da fábrica e um analista de sistemas acreditavam que o alinhamento transparente entre estratégia e operações seria um elemento fundamental para $o$ 
sucesso da GP. Segundo outro gerente de projetos, a delegação de poder é o mais importante fator para que o gerente de projetos desempenhe suas funções de forma satisfatória e para que a GP possa ser considerada plenamente implantada na organização.

\section{Considerações finais}

A pesquisa descrita neste artigo teve por objetivo analisar os fatores críticos de sucesso (FCS) no gerenciamento de projetos em uma empresa de grande porte. Em virtude do atual cenário competitivo e globalizado em que a empresa Alpha está inserida, observou-se que alguns fatores críticos ou exigências para o sucesso se destacaram como: a agilidade, o poder de inovar de forma rápida e eficiente, a capacidade de adaptação e o potencial de aprimoramento contínuo com grandes restrições de recursos. A análise sobre os aspectos relacionados às competências necessárias para a eficiência e eficácia da GP indicou que, de forma geral, os itens considerados mais críticos pela equipe foram os relacionados ao planejamento e suporte gerencial. Em contrapartida, os considerados com menos criticidade são relacionados ao treinamento dos funcionários. Percebeu-se que os gestores devem identificar e mapear aspirações, ambições e perspectivas nos diferentes níveis hierárquicos (juniores e seniores) para alocar as pessoas em posições corretas no desenvolvimento do projeto. Cabe a eles também a tarefa de verificar as especificidades em relação à execução dos projetos para obter ganhos gerenciais, aumentar a eficácia e obter um bom desenvolvimento do trabalho.

Igualmente, verificou-se que, para que os projetos sejam concluídos de forma satisfatória, reduzindo os gargalos dos processos, é necessário que a empresa e a equipe estudada reconheçam a importância da GP como uma metodologia útil para reduzir os riscos de fracasso e que colaborem para a empresa atingir sucesso em seus projetos. Desse modo, dentre os gargalos observados, verificou-se que (i) a aversão às mudanças e (ii) o desconhecimento de processos de gestão retardam o processo de maturidade das empresas. Outros pontos críticos relatados são (iii) que se aumente o número de pessoas na equipe e (iv) se delegue a essa a função de focar em desenvolvimento de projetos de melhoria. Além disso, os entrevistados informaram ser necessário que (v) todos os membros entendam claramente os objetivos do projeto e as expectativas dos stakeholders para aumentar as chances de sucesso.

Os resultados também indicam que a equipe de projetos deve estar muito bem estruturada e conhecer os pontos críticos no gerenciamento. A falta de assimilação e aderência dos processos de GP pode acarretar problemas de cunho estratégico, circunstancial, organizacional e cultural. Nesse sentido, e mesmo que os resultados observados não possam ser indiscriminadamente generalizáveis, a análise do caso mostrou que a adoção da GP pode ser bastante relevante nas empresas, facilitando a elas concretizar o seu planejamento estratégico e romper os obstáculos para alcançar níveis maiores de maturidade.

Observou-se que, embora a percepção dos entrevistados sobre a criticidade dos FCS em GP não seja uniforme, parece haver uma concordância de que o sucesso na GP exige o rigor e a disciplina do uso de um corpo de conhecimentos bem estruturados, assim como um conjunto de habilidades gerenciais relacionadas com a administração geral e alguma vocação para lidar com o desconhecido em um próximo projeto, pois, por definição, cada projeto é único, e o mesmo tipo de projeto implantado em organizações diferentes pode levar a resultados tão opostos como sucesso ou fracasso, em linha com as premissas de Charvat (2003). Sendo importante destacar que, como qualquer outro aspecto da administração, a GP precisa evoluir e se adaptar constantemente às necessidades cada vez mais dinâmicas das organizações. Em resposta a essa dinâmica que afeta todas as empresas, e não só as grandes como a hora analisada, fortalecem-se os sistemas de GP como uma forma de gerir os empreendimentos temporários, únicos e multifuncionais - que colaboram para o processo de implementação de estratégias, adaptação e aprimoramento destas, como sugerido por Hwang \& Lim (2013). Assim, mesmo considerando as limitações de um estudo de caso único como este, pode-se inferir, a partir do conhecimento gerado com a pesquisa, que seria recomendável que gestores aplicassem metodologias estabelecidas (como o PDCA) na melhoria do processo de GP. Adicionalmente, vale notar a necessidade de que a alta administração se comprometa mais com a GP em nível macro e em cada equipe envolvida. Fica, portanto, como sugestão futura de pesquisa a ampliação do escopo desta pesquisa em novos contextos ou através de estudos de larga escala para melhor compreender a dinâmica da GP em grandes empresas.

Além da inovação metodológica trazida pela estratégia de observação participante e pelo foco no curto prazo (que é um dos principais gargalos no estudo dos FCS), ajudando a preencher uma lacuna de investigação na realidade brasileira, essa pesquisa contribui para que executivos, acadêmicos e empresas possam melhor compreender tanto as práticas de GP quanto a dinâmica das ações para mitigar e/ou reduzir os riscos inerentes aos processos e às atividades em grandes empresas.

Como implicações gerenciais da pesquisa, ressalta-se que a identificação dos FCS na empresa estudada e dos indicadores-chave de desempenho pode ajudar a mapear, avaliar e melhorar o desempenho da GP em situações parecidas, sendo esse processo de 
benchmarking um meio de aprendizagem e apoio no processo de melhoria contínua de outras empresas similares, colaborando para que elas possam se manter competitivas.

Do que fora dito, é mister observar que se dê maior dedicação a atividades mais críticas como: planejamento, comunicação efetiva, disposição de processos e ferramentas de planejamento e controle adequados, desenvolvimento de documentação adequada, gerenciamento adequado das mudanças necessárias ao longo do projeto, disponibilização de treinamentos para os gerentes de projetos, dentre outras.

Em síntese, os resultados indicaram que, durante a condução de projetos, o acompanhamento dos FCS de forma oportuna pode ser capaz de impedir o surgimento de problemas ou minimizar o efeito destes. Além disso, observou-se a relevância do acompanhamento constante dos processos empresariais, visando (1) conhecer melhor as atividades realizadas, para identificar problemas potenciais e reais, (2) efetuar correções na dinâmica desses processos e (3) propor mudança nos métodos e ferramentas aplicadas na GP.

\section{Referências}

Alves, E. M. S. P., Davila, G. A., \& Silva, O. F. P. Jr., \& Varvakis, G. J. (2013). Fatores críticos de sucesso na gestão de projetos na perspectiva da gestão do conhecimento: estudo de caso de três empresas projetizadas (pp. 1-19). In Anais do II SINGEP e I S2IS. São Paulo: UNINOVE.

Bardin, L. (2004). Análise de conteúdo (3 ed.). Lisboa: Edições 70.

Campos, E. (2014). Quer ser presidente? Uma pesquisa inédita revela o perfil, os desafios e as fontes de inspiração de 120 líderes das maiores empresas do Brasil. Época Negócios. Recuperado em 03 de março de 2015, de http://epocanegocios.globo.com/Informacao/Resultados/noticia/2014/05/quer-ser-presidente. html

Carvalho, M. M. (1997). QFD uma ferramenta de tomada de decisão em projeto (Tese de doutorado). Departamento de Engenharia Produção e Sistemas, Universidade Federal de Santa Catarina, Florianópolis.

Charvat, J. (2003). Project management methodologies: selecting, implementing, and supporting methodologies and processes for projects. New Jersey: John Wiley.

Cooper, D. R., \& Schindler, P. S. (2006). Business research methods (9 ed.). Nova York: McGraw HillIrwin.

Coutinho, I. A. (2009). Estudo da aderência dos processos de gestão de projetos em empresas de engenharia consultiva de Belo Horizonte (Dissertação de mestrado). PPGA em Administração, Universidade FUMEC, Belo Horizonte.
D’Ávila, M. (2013). PMBOK e gerenciamento de projetos. Recuperado em 03 de janeiro de 2015, de http:// www.mhavila.com.br/topicos/gestao/pmbok.html

Dinsmore, P. C. (2007). A conceptual team-building model: achieving teamwork throught improved communications and interpersonal skills. In P. C. Dinsmore (Ed.), The handbook of project management (4th ed., pp. 81-108) EUA: Amacom.

Eisenhardt, K. (1989). Building theories from case study research. Academy of Management Review, 14(14), 532-500.

George, A., \& Bennett, G. (2005). Case studies and theory development in the social sciences. Cambridge: MIT Press.

Han, W. S., Yusof, A. M., Ismail, S., \& Aun, N. C. (2012). Reviewing the notions of construction project success. International Journal of Business and Management, 7(1), 90-101.

Harvard Business School - HBS. (1997). Project management manual. Boston: Harvard Business School.

Hwang, B., \& Lim, E. J. (2013). Critical success factors for key project players and objectives: case study of singapore. Journal of Construction Engineering and Management, 139(2), 204-215. http://dx.doi. org/10.1061/(ASCE)CO.1943-7862.0000597.

International Organization for Standardization - ISO (1997). ISO 10006: quality management - guidelines to quality in project management. Switzerland: ISO.

Jick, T. (1979). Mixing qualitative and quantitative methods: triangulation in action. Administrative Science Quarterly, 24(4), 602-610. http://dx.doi. org/10.2307/2392366.

Jordão, R. V. D., Novas, J. C., Souza, A. A., \& Neves, J. T. R. (2013). Controle do capital intelectual: um modelo aplicado à gestão dos ativos do conhecimento. $R e$ vista Iberoamericana de Estratégia, 12(2), 195-227.

Kerzner, H. (1992). Project management: a systems approach to planning, scheduling and controlling. New York: Van Nostrand Reinhold.

Kerzner, H. (2002). Strategic planning for project management using a project management maturity model. New York: John Wiley \& Sons.

Kloppenborg, T. J., \& Opfer, W. A. (2002). The current state of project management research: trends, interpretations, and predictions. Project Management Journal, 33(2), 5-18.

Morioka, S., \& Carvalho, M. M. (2014). Análise de fatores críticos de sucesso de projetos: um estudo de caso no setor varejista. Produção, 24(1), 132-143.

Ofori, D. F. (2013). Project management practices and critical success factors - a developing country perspective. International Journal of Business and Management, 8(21), 14-31. http://dx.doi.org/10.5539/ ijbm.v8n21p14. 
Oliveira, L. H. (2005). Exemplo de cálculo de ranking médio para Likert. Varginha: CNEC/FACECA. Notas de aula da disciplina metodologia científica e técnicas de pesquisa em administração.

Olson, E. M., Walker, O. C., Jr., Ruekerf, R. W., \& Bonnerd, J. M. (2001). Patterns of cooperation during new product development among marketing, operations and R\&D: Implications for project performance. Journal of Product Innovation Management, 18(4), 258271. http://dx.doi.org/ 10.1111/1540-5885.1840258.

Pinto, J. K., \& Slevin, P. (1987). Critical factors in successful project implementation. IEEE Transactions on Engineering Management, 34(1), 22-27. http://dx.doi. org/10.1109/TEM.1987.6498856.

Premkumar, G., \& King, W. R. (1992). An empirical assessment of information systems planning and the role of information systems in organizations. Journal of Management Information Systems, 9(2), 99-125.

Project Management Institute - PMI (2013). Project management body of knowledge. Pennsylvania: PMI Product.

Rabechini, R., jr., Carvalho, M. M., \& Laurindo, F. J. B. (2002). Fatores críticos para implementação de gerenciamento por projetos: o caso de uma organização de pesquisa. Produção, 12(2), 28-41.

Raz, T., Shenhar, A. J., \& Dvir, D. (2002). Risk management, project success, and technological uncertainty. $R \&$ D Management, 32(2), 101-109. http://dx.doi. org/10.1111/1467-9310.00243.

Rockart, J. F. (1979). Chief executives define their own data needs. Harvard Business Review, 57(2), 81-93. PMid:10297607.

Ruuska, I., \& Vartiainen, I. (2003). Critical project competence: a case study. Journal of Workplace Learning, 15(7/8), 307-312. http://dx.doi. org/10.1108/13665620310504774.

Shenhar, A. J. (2004). Strategic Project Leadership ${ }^{\circledR}$ Toward a strategic approach to project management.
$R \& D$ Management, 34(5), 569-578. http://dx.doi. org/10.1111/j.1467-9310.2004.00363.x.

Shenhar, A. J., Dvir, D., \& Levy, O. (1997). Mapping the dimensions of project success. Project Management Journal, 28(2), 5-13.

Shenhar, A. J., Dvir, D., Levy, O., \& Maltz, A. C. (2001). Project success: a multidimensional strategic concept. Long Range Planning, 6(34), 699-725. http://dx.doi. org/10.1016/S0024-6301(01)00097-8.

Tandon, R., \& Mohanty, R. (2003). Does civil society matter? Governance in contemporary. London: Sage Publications.

Toledo, J. C., Silva, S. L., Mendes, G. H. S., \& Jugend, D. (2008). Fatores críticos de sucesso no gerenciamento de projetos de desenvolvimento de produto em empresas de base tecnológica de pequeno e médio porte. Revista Gestão \& Produção, 15(1), 117-134.

Vallabbaneni, S. R. (2002). Do great engineers make good managers? Engineering Management Journal, 18(2), 146-146.

Vezzoni, G., Pacagnella, A. C., Jr., Banzi, A. L., Jr., \& Silva, S. L. (2013). Identificação e análise de fatores críticos de sucesso em projetos. Revista de Gestão $e$ Projetos - GeP, 4(1), 116-137.

Whitten, N. (2000). How technical must a project manager be? Newton Square: Project Management Institute, Inc.

Wu, C. W., \& Chen, C. L. (2006). An integrated structural model toward successful continuous improvement activity. Technovation, 26(5/6), 697-707. http://dx.doi. org/10.1016/j.technovation.2005.05.002.

Yaraghi, N., \& Langhe, R. G. (2011). Critical success factors for risk management systems. Journal of Risk Research, 14(5), 551-581. http://dx.doi.org/10.1080/1 3669877.2010 .547253$.

Yin, R. (1984). Case study research: design and methods. Beverly Hills: Sage Publishing. 